\title{
INVESTIGATION OF THE MECHANISM ON PROGRESS FOR STRENGTH AND AIR PERMEABILITY OF CONCRETE USING C-S-H HARDENING ACCELERATOR
}

\author{
"Takeshi IYODA ${ }^{1}$, Tomomi SUGIYAMA ${ }^{2}$ \\ 13-7-5, Toyosu, Koto-ku, Tokyo 135-8548, Japan, \\ iyoda@ shibaura-it.ac.jp, Shibaura Institute of Technology \\ ${ }^{2} 2722$ Hagisono, Chigasaki-shi, Kanagawa, Japan, \\ tomomi.sugiyama@basf.com, BASF Japan
}

\begin{abstract}
There are some researches which are progressing to apply C-S-H hardening accelerator in concrete. This admixture is an effective material for accelerating the gain in compressive strength at early ages, this can make possible to increase productivity of concrete structures and products due to the earlier framework removal. In this research, first it is focused on the progress of compressive strength at early age and its development as water cement ratio vary from low to high. Second, it is focused on the durability parameters such as air and water permeability as well as improvement in porosity at interfacial tradition zone. This study investigated using two analyses. One focusing in the examination of the adding method of C-S-H hardening accelerator and its proportions and the other analyzes the porosity area improvement contributed by the C-S-H hardening accelerator. As a result, the addition of C-S-H nanoparticles makes a more effective precipitation site when added over unit of water amount than compared with the conventional addition over cement. This effect is recognized in the interfacial transition zone with low amount of C-S-H addition. It was also found that the mortar part of concrete was modified by high amount of hardening accelerator addition. Finally, we got the effect of densifying the pores in the interfacial transition zone area was observed in a small amount of $\mathrm{CSH}$ hardening accelerator. On the other hand, densification of the bulk portion is also recognized by the addition of a large amount of $\mathrm{CSH}$ hardening accelerator, so it is considered that the added amount influences the properties of the concrete.
\end{abstract}

Keywords: Concrete, air permeability, C-S-H hardening accelerator.

\section{INTRODUCTION}

In the case of improving the reuse of formwork in concrete manufactured products or promote curing in construction sites during winter, the use of a hardening accelerator may be considered. Generally, a nitrite hardening type of accelerator is used. In this case, the mechanism of hardening acceleration promotes cement hydration reaction by dissolution of ions from cement particles what contribute to increase compressive strength. In recent years, a C-S-H hardening accelerator type was developed and produced for market. This hardening accelerator has different mechanism for 
accelerating compressive strength and hardening when compared with the nitrite accelerator. This C-S-H-based hardening accelerator contains nanoparticles of calcium silicate hydrate (hereinafter referred to as $\mathrm{CSH}$ ) as a main component, and by introducing crystal nanoparticles of $\mathrm{CSH}$ into the liquid phase, it promotes hardening without waiting for the generation of $\mathrm{CSH}$ from anhydrate cement. As an application of such CSH hardening accelerator, it has been examined the possibility of improvements by shortening the time for steam curing of manufactured concrete products and the effects of high temperature curing at low water cement ratio. According to many reports, the addition of the CSH hardening accelerator develops the compressive strength at early age and also at long-term. In general, it is difficult to get the progress of long-term compressive strength using conventional accelerators, because the hydration stops on early age due to dissolution of ions from cement. On the other hand, in construction site, concrete with more high water cement ratio is used, however there are not many examples of applications and investigations regarding the $\mathrm{CSH}$ hardening accelerator, and also there are not enough investigation on durability. In general, the chemical admixture is used by being dissolved in the water for kneading. In this method, water is added as a mass ratio of cement, it is because the conventional hardening accelerator acts on the cement. However, since the CSH type hardening accelerator type adds nanoparticles of $\mathrm{CSH}$, its concentration amount is considered to be important. Therefore, rather than considering the weight of cement, it is considered that the weight of unit water amount is important for the method of adding this chemical admixture. On the other hand, it is conceivable that, the cause of the strength development and the improvement of the durability by adding the CSH type hardening accelerator is due to the densification of the pores in the concrete. However, it is unclear which area in the concrete pores are densified by addition of the $\mathrm{CSH}$ hardening accelerator type, and it is necessary to investigate. Particularly in the case of strength and mass transfer resistance, the contributing pore diameter may be different.

In view of the above, this study aims to clarify the method of adding CSH hardening accelerator type and give more information about the modification in pores and pore area to be densified by addition ratio, by changing the water cement ratio and the aggregate quantity.

\section{STRENGTH DEVELOPMENT TEST AT CONSTANT CONCENTRATION IN UNIT WATER AMOUNT}

\subsection{Outline of Experiments}

This study is focused on the hardening promotion mechanism of the CSH hardening accelerator. Therefore, it was considered that it is necessary not to add the admixture over the mass of cement like it is usually done, but to keep constant its concentration in the unit of water. Table 1 shows the materials used in this research.

In order to make same addition amounts of CSH type of hardening accelerator in the mix proportion of concrete, the water unit was made constant, as can be seen on table 2 , and en different water cement ratio such as 40 and $60 \%$ were used. Compressive strength tests in JIS methods were carried out in a total of three patterns en of addition of CSH hardening accelerator being them $\mathrm{W} \times 10 \%$ - with $10 \%$ oven the water amount, 
$\mathrm{C} \times 4 \%$ - ordinary addition over the cement amount, and ACX0\% - with no addition (hereinafter referred to as ACX 0\%). Also, in order to confirm the mass transfer resistance, an air permeability test was carried out. Two cylindrical specimens of $\varnothing 100 \times 50 \mathrm{~mm}$ were prepared and each specimen were subjected to sealing curing in an environment of constant temperature and humidity $\left(20^{\circ} \mathrm{C}, 60 \% \mathrm{RH}\right)$. Concrete samples were left to stand in a drying oven at 40 degrees Celsius until constant weight to remove moisture contained in the pores. By giving a constant pressure of $0.2 \mathrm{~N} / \mathrm{cm}^{2}$ to the specimen, the permeated air was measured by the water replacement method, and the air permeability coefficient was calculated from the air permeation amount obtained.

\begin{tabular}{|c|c|c|}
\hline \multicolumn{3}{|c|}{ Table 1 Used materials in this research } \\
\hline Material & Symbol & Types and physical properties \\
\hline Water & $\mathrm{W}$ & Water supply \\
\hline \multirow{2}{*}{ Binder } & OPC & Ordinary Portland cement (Density:3.16g/ $\mathrm{cm}^{3}$ ) \\
\hline & BFS & Blast furnace slag (Density:2.91g/ $/ \mathrm{cm}^{3}$ ) \\
\hline Sand aggregate & $S$ & Mountain sand (Density:2.62g/ $\mathrm{cm}^{3}$ ) \\
\hline Coarse aggregate & G & Limestone (Density:2.70g/ $/ \mathrm{cm}^{3}$ ) \\
\hline \multirow{3}{*}{ Admimxture } & SP & High performance $\mathrm{AE}$ water reducing agent \\
\hline & $\mathrm{AE}$ & AE agent \\
\hline & $\mathrm{ACX}$ & CSH type hardening accelerator \\
\hline
\end{tabular}

Table 2 Mix proportions for different water cement ratio

\begin{tabular}{|c|c|c|c|c|c|c|c|c|c|c|c|c|c|c|}
\hline \multirow{3}{*}{$\begin{array}{l}\mathrm{W} / \mathrm{C} \\
(\%)\end{array}$} & \multirow{3}{*}{$\begin{array}{l}\mathrm{s} / \mathrm{a} \\
(\%)\end{array}$} & \multirow{3}{*}{$\begin{array}{c}\text { air } \\
(\%)\end{array}$} & \multicolumn{5}{|c|}{ Unit amount $\left(\mathrm{kg} / \mathrm{m}^{3}\right)$} & \multicolumn{2}{|c|}{ ACX } & \multicolumn{2}{|c|}{ Admixture } & \multicolumn{3}{|c|}{ Fresh results } \\
\hline & & & \multirow{2}{*}{$\mathrm{W}$} & \multicolumn{2}{|c|}{ B } & \multirow{2}{*}{ S } & \multirow{2}{*}{$\mathrm{G}$} & \multirow{2}{*}{$\begin{array}{c}\text { Addtion rate } \\
(\%)\end{array}$} & \multirow{2}{*}{$\begin{array}{l}\text { Addition amont } \\
(\mathrm{kg})\end{array}$} & \multirow{2}{*}{ SP } & \multirow{2}{*}{$\mathrm{AE}$} & \multirow{2}{*}{$\mathrm{CT}\left({ }^{\circ} \mathrm{C}\right)$} & \multirow{2}{*}{$\begin{array}{l}\text { Slump } \\
(\mathrm{cm})\end{array}$} & \multirow{2}{*}{$\operatorname{air}(\%)$} \\
\hline & & & & OPC & BFS & & & & & & & & & \\
\hline \multirow{3}{*}{40} & \multirow{3}{*}{44} & \multirow{6}{*}{4.5} & \multirow{6}{*}{170} & \multirow{3}{*}{213} & \multirow{3}{*}{213} & \multirow{3}{*}{743} & \multirow{3}{*}{975} & 0 & - & $0.40 \%$ & $4.5 \mathrm{~A}$ & 20.8 & 13.0 & 4.0 \\
\hline & & & & & & & & $\mathrm{C} \times 4 \%$ & 17.0 & \multirow{2}{*}{$0.30 \%$} & \multirow{2}{*}{$2.5 \mathrm{~A}$} & \multirow{2}{*}{22.5} & \multirow{2}{*}{10.5} & \multirow{2}{*}{4.5} \\
\hline & & & & & & & & $\mathrm{W} \times 10 \%$ & 17.0 & & & & & \\
\hline \multirow{3}{*}{60} & \multirow{3}{*}{48} & & & \multirow{3}{*}{142} & \multirow{3}{*}{142} & \multirow{3}{*}{870} & \multirow{3}{*}{971} & 0 & - & $0.40 \%$ & $3.5 \mathrm{~A}$ & 20.8 & 19.5 & 3.9 \\
\hline & & & & & & & & $\mathrm{C} \times 4 \%$ & 11.4 & $030 \%$ & $4.5 \mathrm{~A}$ & 21.1 & 18.0 & 3.6 \\
\hline & & & & & & & & $\mathrm{W} \times 10 \%$ & 17.0 & $0.30 \%$ & $5.0 \mathrm{~A}$ & 21.3 & 20.0 & 3.5 \\
\hline
\end{tabular}

\subsection{Test Results}

The results of compressive strength test are shown in Figure 1. As can be seen from the figure, the strength enhancement was observed at water cement ratio of $40 \%$ from $\mathrm{ACX} 0 \%$ to $\mathrm{CX} 4 \%$. When added at $\mathrm{C} \times 4 \%$ in the water cement ratio of $60 \%$, the strength development due to the addition of the CSH type of hardening accelerator does not vary remarkably compared with that with ACX $0 \%$. On the other hand, when $\mathrm{W} \times 10 \%$ was added, strength development was confirmed for both water cement ratios. The increase rate of $\mathrm{C} \times 4 \%$ of standard added amount at water cement ratio of $60 \%$ is about the same or lower than that of ACX $0 \%$, whereas when $\mathrm{W} \times 10 \%$ it is confirmed that the strength increase is about $20 \%$ compared with that of ACX 0\%. From the above results, when the CSH type of hardening accelerator is added in proportion to the mass of cement, no strength development is observed at the high water cement ratio, but when added at a constant ratio to the unit water amount, all the water cement 
ratio, it was possible to confirm the strength development of the CSH type of hardening accelerator.

The results of the air permeation test are shown in Figure 2. The reduction of the air permeability coefficient was recognized by adding the amount of the CSH type of hardening accelerator compared with ACX $0 \%$ in both water cement ratio as $40 \%$ and $60 \%$. In addition, the effect of improving the air permeability was large on water cement ratio as $60 \%$, which has a larger pore volume than $40 \%$ with has a dense pore structure. Therefore, it was found that as the water cement ratio is high and the voids are larger, the air voids becomes denser and the air permeability coefficient becomes smaller by adding the CSH type hardening accelerator.
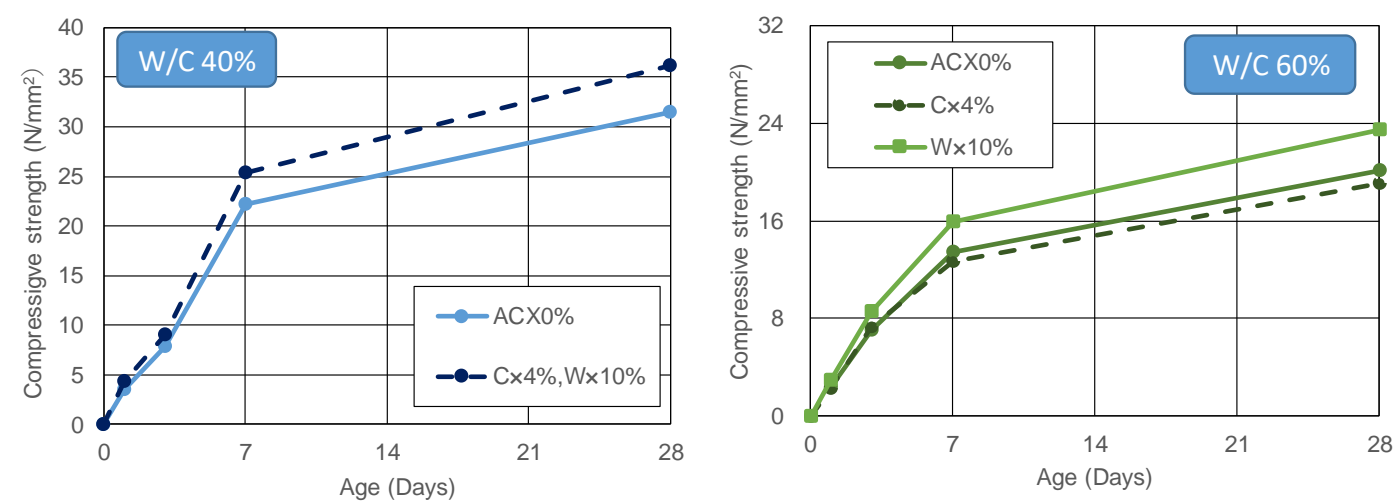

Figure 1 Progress of compressive strength on different amount of ACX

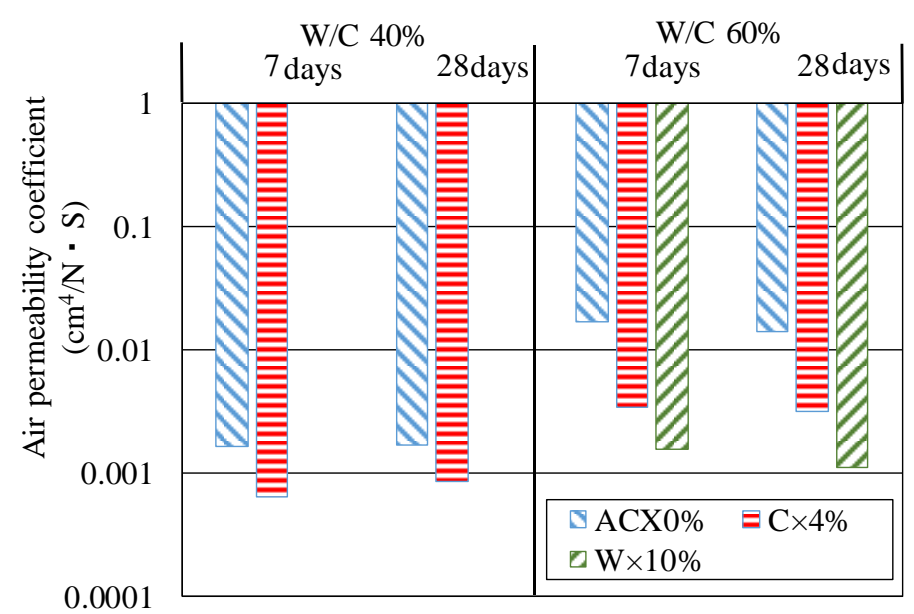

Figure 2 Results of air permeability coefficient on different amount of ACX

\section{INVESTIGATION OF DENSIFIED PORE DIAMETER}

From the above, it was revealed that only the mass transfer resistance was reformed at a low addition of the $\mathrm{CSH}$ type hardening accelerator at high water cement ratio. On the other hand, the mass transfer resistance and strength development were modified at high addition of CSH type of hardening accelerator on high and low water cement ratio. Therefore, it was decided to examine the mechanism that modify the pore area, 
the enhancement of the strength and the modification of the mass transfer characteristics, especially focusing on the gap between the interfacial transition zone and the capillary pore in mortar.

\subsection{Outline of Experiment}

Assuming that the concrete pores are in the interfacial transition zones, at the interface of the coarse aggregate in the concrete, and capillary pores are in the mortar, for this study, the amount of coarse aggregate in concrete was varied on same water cement ratio as 0.50 in order to change the amount of interfacial transition zone. The sand aggregate ratios were set as $40 \%, 48 \%, 56 \%$ on mix proportions in order to vary the amount of coarse aggregate in concrete. As a result, the amount of coarse aggregate increases and the interfacial transition zone volume also increases due to internal bleeding formed on the lower surface of aggregate. At the same time, it was also prepared mortar (sand aggregate ratio of $100 \%$ ), to investigate those without interfacial transition zone around coarse aggregate. Table 3 shows the mix proportions of the prepared experiment. With respect to the addition of the CSH type of hardening accelerator, the addition amounts in concrete with sand aggregate ratio of $48 \%$ were set as $\mathrm{W} \times 0 \%, 10 \%, 20 \%$, and $30 \%$. The same amounts of admixture (CSH) were added to other sand aggregate ratio. In other words, the unit amount of admixture in concrete is the same. Concrete was prepared using an omni mixer and the specimens were tested in order to measure the mass permeability such as the air permeability test and the total pore volume. The curing of the specimen was sealed for 7 days in an environment at 20 degrees Celsius. For the porosity test such as Archimedes method, the specimen was used after the air permeability test. The specimens were dried in a drying oven at 40 degrees Celsius, and measured the at constant weight as the absolute dry state, after that, vacuum saturation treatment was performed to measure the weight at saturated water mass and at in the water to calculate the total porosity.

Table 3 Mix proportion of investigation for densified pore size

\begin{tabular}{|c|c|c|c|c|c|c|c|c|c|}
\hline \multirow[b]{2}{*}{ Symbol } & \multirow[b]{2}{*}{$\mathrm{W} / \mathrm{C}$} & \multirow[b]{2}{*}{ s/a (\%) } & \multirow[b]{2}{*}{$\operatorname{air}(\%)$} & \multicolumn{4}{|c|}{ Unit amount $\left(\mathrm{kg} / \mathrm{m}^{3}\right)$} & \multicolumn{2}{|c|}{$\mathrm{ACX}$} \\
\hline & & & & $\mathrm{W}$ & $\mathrm{C}$ & S & G & Ratio (\%) & $\begin{array}{c}\text { Dosage } \\
(\mathrm{kg})\end{array}$ \\
\hline \multirow{4}{*}{$50 \%-56$} & \multirow{12}{*}{$50 \%$} & \multirow{4}{*}{56} & \multirow{12}{*}{4.5} & \multirow{4}{*}{190} & \multirow{4}{*}{380} & \multirow{4}{*}{951} & \multirow{4}{*}{761} & $\mathrm{~W} \times 0 \%$ & - \\
\hline & & & & & & & & $\mathrm{W} \times 9 \%$ & 17 \\
\hline & & & & & & & & $\mathrm{W} \times 18 \%$ & 34 \\
\hline & & & & & & & & $\mathrm{W} \times 27 \%$ & 51 \\
\hline \multirow{4}{*}{$50 \%-48$} & & \multirow{4}{*}{48} & & \multirow{4}{*}{170} & \multirow{4}{*}{340} & \multirow{4}{*}{852} & \multirow{4}{*}{951} & $\mathrm{~W} \times 0 \%$ & - \\
\hline & & & & & & & & $\mathrm{W} \times 10 \%$ & 17 \\
\hline & & & & & & & & $\mathrm{W} \times 20 \%$ & 34 \\
\hline & & & & & & & & $\mathrm{W} \times 30 \%$ & 51 \\
\hline \multirow{4}{*}{$50 \%-40$} & & \multirow{4}{*}{40} & & \multirow{4}{*}{150} & \multirow{4}{*}{300} & \multirow{4}{*}{752} & \multirow{4}{*}{1141} & $\mathrm{~W} \times 0 \%$ & - \\
\hline & & & & & & & & $\mathrm{W} \times 11 \%$ & 17 \\
\hline & & & & & & & & $\mathrm{W} \times 23 \%$ & 34 \\
\hline & & & & & & & & $\mathrm{W} \times 34 \%$ & 51 \\
\hline
\end{tabular}




\subsection{Experiment Results}

(1) Porosity Test

The results of the porosity test are shown in Figure 3. Mortar [50\% -100] resulted in larger pore volume by when compared with concrete. This is because the coarse aggregate is considered to have less pores, and it is assumed that the interfacial transition zone and the capillary pores exists in the mortar portion excluding the coarse aggregate. So the experiment results are evaluated per unit of mortar in the concrete. The results are shown in Figure 4. When CSH type of hardening accelerator is not added, it is understood that concrete has more pores than mortar. It is considered that the difference from mortar is a that the pores are mainly located at the interfacial transition zone on the interface of the coarse aggregate. Next, it can be seen that the porosity decreases in any compounding by adding the CSH type hardening accelerator.
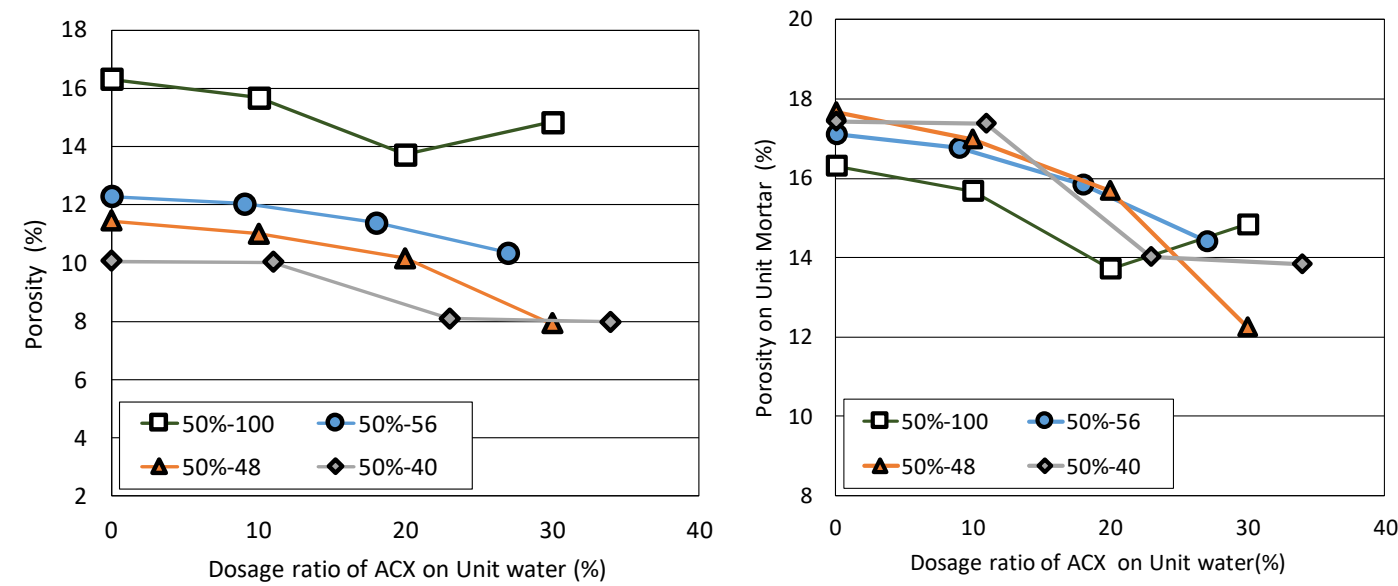

Figure 3 Porosity of different dosage of ACX Figure 4 Porosity on Unit Mortar

(2) Air permeability test

The results of the air permeation test are shown in Figure 5. The coarse aggregate was considered not to let air permeate, and it was expressed by the air permeability coefficient per unit mortar. It can be seen that the air permeability coefficient decreases in any compounding by increasing the amount of CSH type of hardening accelerator. For concrete with varying amount of coarse aggregate, the coarse aggregate amount is larger and the amount of interfacial transition zone is considered to be larger. The permeability coefficient of [50\%-40] is greatly improved by the addition of CSH type of hardening accelerator. 


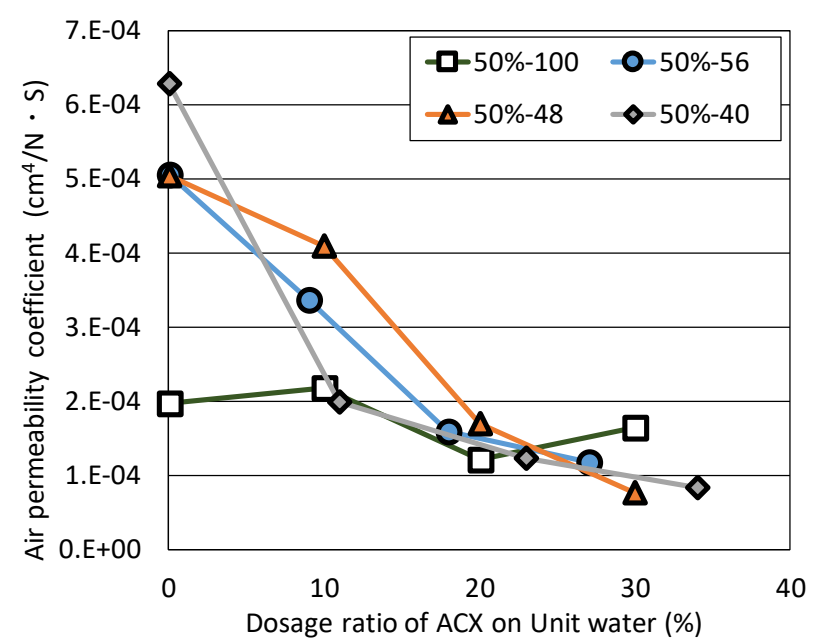

Figure 5 Results of air permeability coefficient on different dosage ACX

\subsection{Consideration of Densified Pore Diameter}

Figure. 6 shows the relationship between the porosity per unit mortar and the air permeability coefficient. It is found that the air permeability coefficient improves as the porosity improves. This relationship also showed the same tendency in the mix proportion in which the amount of coarse aggregate was changed. In the relationship between the porosity and the air permeability coefficient, the tendency differs between the absence of the CSH type of hardening accelerator and the addition amount from of small to large. By adding a small amount of the CSH type of hardening accelerator, the reduction of the gaps is small but the decrease of the air permeability coefficient becomes larger. This tendency was particularly conspicuous at [50\%-40], which is the largest amount of coarse aggregate. On the other hand, as the addition amount of CSH hardening accelerator increased, the relationship showed that the air permeability coefficient became smaller as the porosity decreased, and the same tendency was observed for both mortar and concrete. Considering this fact, as shown in Figure 7, the variation due to the difference in the added amount of CSH hardening accelerator, when adding a small amount, the nanoparticles of CSH are generated in the interfacial transition zone area between the coarse aggregate and the cement hardened. It can be inferred that in the capillary pores occurs a hydration reaction that modifies the pores in the mortar, when the hydration reaction of the cement takes place to a certain extent. Therefore, in the case of addition of a small amount of CSH hardening accelerator on high water cement ratio, the hydration products are formed in larger pores, so the influence on strength is not large and-permeability is improved.

On the other hand, it can be imagined that both the strength and the durability are influenced by the densification of the pores of the mortar itself rather than the interfacial transition zone area due to the low water cement ratio. In the future, we think that it is good to express the mechanism of the effect quantitatively from a method such as direct observation using SEM. 


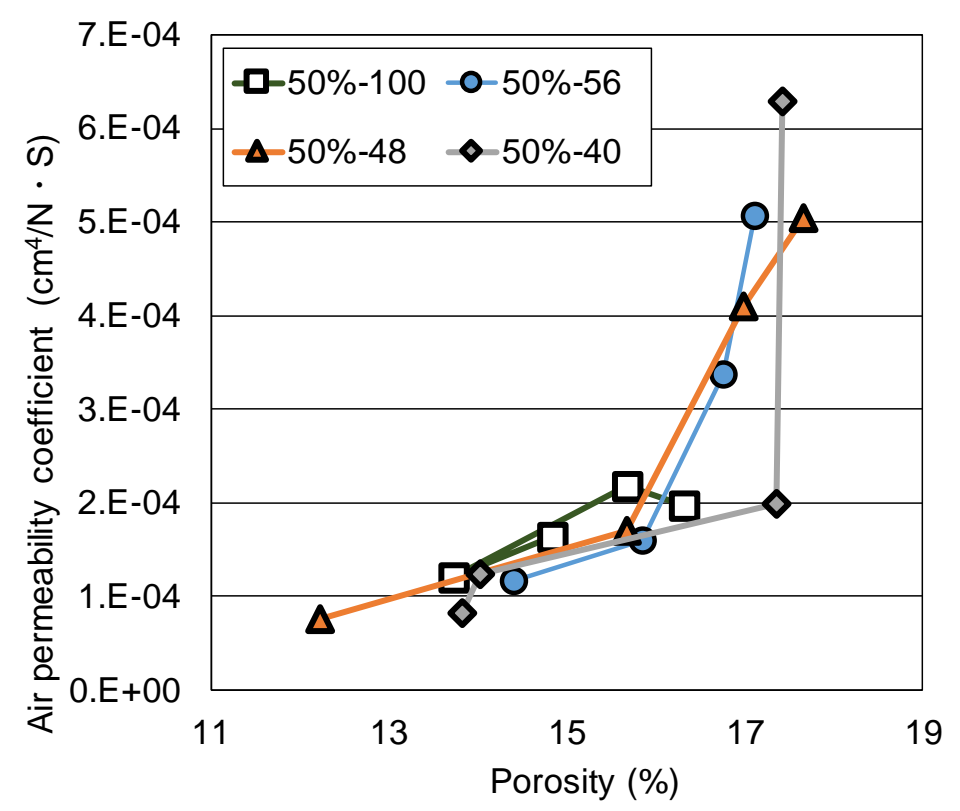

Figure 6 Relationship between porosity and air permeability coefficient

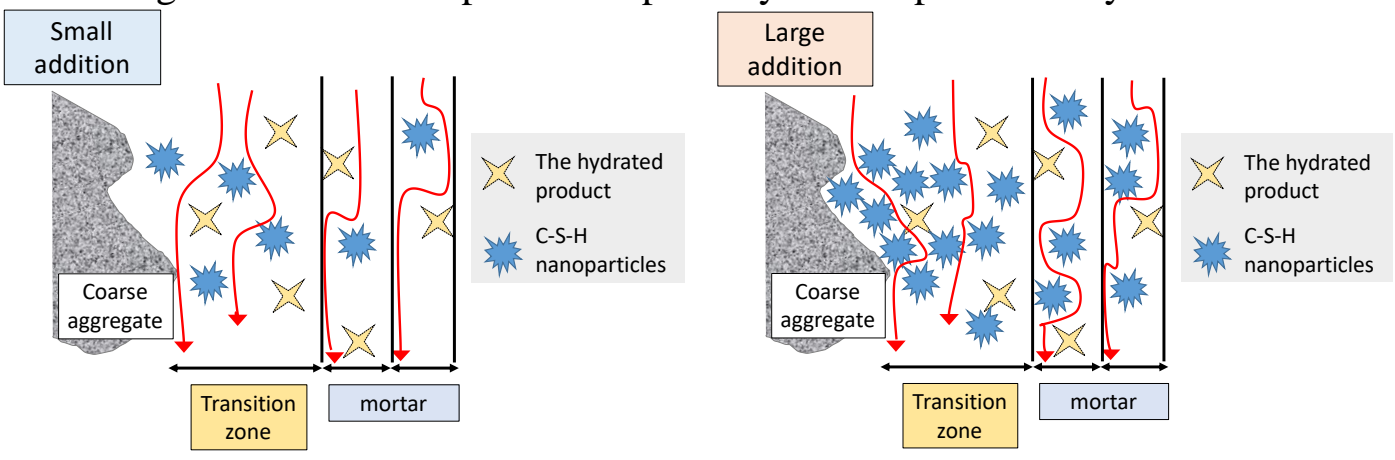

Figure 7 Image of densified pore using different amount of ACX

\section{CONCLUSION}

The results obtained in this research are summarized below.

(1) Because the $\mathrm{CSH}$ hardening accelerator which is a new material, acts on the concentration in unit water instead of affecting cement, it is desirable to add the concentration to the unit water amount.

(2) When the water cement ratio was high, the effect of densifying the pores in the interfacial transition zone area was observed in a small amount of CSH hardening accelerator. Densification of the bulk portion is also recognized by the addition of a large amount of CSH hardening accelerator, so it is considered that the added amount influences the properties of the concrete.

\section{FUTURE WORK}

(1) In this research, it could not be directly observed and measured the Interfacial 
transition zone. For future research, it will be conducted directly observation and to clarify the information about the transition zone using SEM and MIP.

(2) It was ascertained that the permeability resistance of the material was different when liquid water or gas was used. For this reason, it is important further investigation considering viscosity and etc.

(3) As a study to minimize the interfacial transition zone, we would like to evaluate methods such as adsorption of this CSH hardening accelerator by the aggregate.

\section{ACKNOWLEDGMENTS}

This study summarizes the research results of former Shibaura Institute of Technology graduate students Mr. Minami, Ms. Ushikubo and thanks to both of them.

\section{REFERENCES}

Imoto, H., Hanabusa, K., Koizumi, S. and Sugiyama, T. (2015). Effect of C-S-H type hardening accelerator on strength development of concrete using blast furnace cement, Proceedings of the Japan Concrete Institute, vol. 37, no. 1, pp. 175180.

Koizumi, S., Imoto, H., Baba, Y. and Yamazaki, Y. (2014). Study on strength development and durability of concrete using C-S-H type hardening accelerator, Proceedings of the Japan Concrete Institute, vol. 36, no. 1, pp. 154-159.

Onda, Y., Ishizawa, M., Sasaki, W. and Taniguchi, H, (2015). Strength and heating characteristics of concrete using various curing promoting material, Technical research report of Sumitomo Mitsui Construction, no. 13, pp. 49-54.

Oyama, H., Imoto, H., Koizumi, S., and Tsuchiya, T. (2017). Characteristics and effects of early strengthening agent containing C-S-H type nanoparticles, Japan Concrete Institute, Technical report, Journal Concrete Engineering, Vol. 53, no. 7.

Nakanishi, Y., Minami, H., Sugiyama, T., and Iyoda, T. (2017). Effects of C-S-H type hardened accelerator in unit water amount on strength and durability, Japan society of civil engineers annual meeting, vol. 5, no. 1, pp. 669-670.

Tagomori, K., Nakanishi, Y. and Iyoda, T. (2018). Effect of bleeding on aggregate interstitial pore formation on material permeability, Proceedings of the Japan Concrete Institute, vol. 40, no. 1, pp. 111-116. 